\title{
PASTEURELLOSIS IN CAGE BIRDS AT ZOOLOGICAL PARK, JAIPUR
}

\author{
P.K. Mehrotra1 ${ }^{1}$, Sudhir Bhargava ${ }^{2}$, Sheela Chaudhary ${ }^{3}$ and B.B.L. Mathur ${ }^{4}$ \\ ${ }^{1}$ Officer-in-charge (Associate Professor-Microbiology), ${ }^{2}$ Instructor, ${ }^{3}$ Assistant Professor \\ Apex Centre (Animal Disease Investigation, Monitoring and Surveillance Centre), A.R.S. Campus, Durgapura, Jaipur, Rajasthan, India. \\ ${ }^{4}$ Veterinary Officer, Zoological garden, Jaipur, Rajasthan, India.
}

\begin{abstract}
Postmortem examination of eight dead birds in Jaipur Zoo revealed the cause of mortality as pneumonia. The blood and visceral organ samples cultured revealed the presence of five bacterial species. Stress manifestation in birds in the form of pneumonic or generalized septicaemia due to pasteurellosis is a common occurence as reported by many workers before and in this paper.
\end{abstract}

\section{Introduction}

Pasteurellosis in domestic animals is of great concern to veterinary practitioners. Commensal, saprophytic and pathogenic status of Pasteurella species have been well established. Pasteurella multocida, Pasteurella haemolytica and Pasteurella aeiseptica are known to be associated with septicaemic type of diseases in domestic mammals and birds. In India, this disease has enzootic as well as epizootic proportions which usually occurs following some stress like weather change, low temperature or cold waves, high humidity, transportation, overcrowding etc. In cage birds, tendency of hurdling together further enhances the occurence of respiratory form of pasteurellosis.

The Zoological Park, Jaipur had sporadic cases of pasteurellosis of birds in winter season. Different types of birds were kept in different bird enclosures.

Mortality due to pneumonia or septicaemia was recorded in Indian Pied Hornbill (1), Wild hen and cock (3), Pigeons (3) and Indian Black Kite (1). All birds had history of listlessness, refusing to eat and drink, open beak, and rapid breathing. There was marked nasal discharge and in case of wild cock there was cyanosis of comb and wattles. Death occurred in 1-3 days of illness.

Rceceived on 22 July 1999 Accepted on 3 March 2000

\section{Diagnosis}

The birds which succumbed to sudden illness, were subjected to postmortem examination. The important pathological findings include petechia and ecchymoses involving serous surfaces of abdominal fat, haemorrhages in heart and gizzard. Petechial haemorrhages in lungs and mucosa of intestine were invariably encountered in all cases. Small haemorrhages and congestion in duodenal part of intestines, with thick, viscid mucous accumulations in the lumen were present more prominantly in Hornbill and hens in contrast to kites and pigeons. Enlargement of liver, brownish and yellowish discoloration and enhanced friability were common in all birds. Numerous pin point to pin head size necrotic foci were present on liver surfaces. Proventriculus and crop were found empty. There were mild catarrhal to congestive enteritis. The general musculature presented severe congestion. Congestive air sacculitis was the striking character in all cases with variable degree of haemorrhages.

The lung pieces, heart blood, long bones and spleen pieces were collected for demonstration and isolation of causal agent. The blood smears and impression smears from various organs including bone marrow, revealed the presence of bipolar rods following staining with Methylene blue and Giemsa's. These morphological structures were indistinguishable from Pasteurellae.

All blood samples and visceral organs were inoculated in glucose broth medium for isolation of causal agent. The bacterial growth appearing following incubation of inoculated broth medium at $37^{\circ} \mathrm{C}$ for $12-16 \mathrm{hrs}$ were reinoculated in blood agar medium. The colonies appearing in blood agar medium subjected to bacteriological identification test as per technique of Carter (1965). The details of bacterial species identified, source and the number is depicted in Table 1.

Blood smears prepared from heart blood and stained with Giemsa's were subjected to differential leucocytic counts and the results are given in Table 2. 
Table 1. Number, source and bacterial species identified from morbid specimen.

\begin{tabular}{llll}
\hline $\begin{array}{l}\text { Type } \\
\text { and No. } \\
\text { of birds }\end{array}$ & Organ or Tissue & $\begin{array}{l}\text { No. of } \\
\text { samples }\end{array}$ & $\begin{array}{l}\text { Bacterial } \\
\text { isolate identified }\end{array}$ \\
\hline Indian Pied & Blood (Heart) & 1 & P. multocida \\
Hornbill & Lung & 1 & $\begin{array}{l}\text { P. multocida and P. haemolytica } \\
(1)\end{array}$ \\
& Spleen & 1 & P. multocida \\
& Liver & 1 & P. multocida \\
Hen / Cock & Blood (Heart) & 3 & P. multocida \\
$(3)$ & Lung & 3 & P. multocida, Staphylococcus aureus, Streptococcus sp. \\
& Spleen & 3 & P. multocida \\
& Liver & 3 & P. multocida \\
Pigeons & Blood (Heart) & & P. multocida \\
$(3)$ & Lung & 3 & P. multocida \\
& Spleen & 3 & P. multocida \\
& Liver & 3 & P. multocida \\
Indian & Blood (Heart) & 3 & P. multocida \\
Black Kite & Lung & P. multocida, P. haemolytica \\
$(1)$ & Spleen & 1 & None \\
& Liver & 1 & None \\
\hline
\end{tabular}

Table 2. Mean per cent values of differential leucocyte counts of different birds succumbed to pasteurellosis.

\begin{tabular}{ll|lllll}
\hline Birds & $\begin{array}{l}\text { No.of } \\
\text { samples }\end{array}$ & \multicolumn{5}{|c}{ Mean per cent values } \\
\cline { 3 - 7 } & & Lymphocytes & Heterophils & Monocytes & Eosinophils & Basophils \\
\hline Indian Pied Hornbill & 1 & 61 & 82 & 4 & 2 & 1 \\
Hen/Cock & 3 & 59 & 28 & 8 & 2 & 3 \\
Pigeons & 3 & 63 & 31 & 4 & 1 & 1 \\
Indian Black Kite & 1 & 67 & 24 & 7 & 1 & 1 \\
\hline
\end{tabular}

Pasteurella multocida and Pasteurella haemolytica identified were tested for their antibiotic sensitivity against a set of seven antibiotic or chemotherapeutic agents commonly employed in cases of pasteurellosis. The antibiotic resistance pattern of isolates are given in Table 3.

\section{Discussion}

The clinical history, observations on postmortem examination and clinical findings were suggestive of pasteurellosis either in pneumonic or generalized septicaemic form, which could cause heavy morbidity and mortality amongst the birds due to either weather stress or some other factors. Pigeons and Horn- bill were found comparatively to be more sensitive to the pneumonic form of pasteurellosis than poultry or Kite and they suffer more by septicaemic form.

The antibiotic sensivity pattern of Pasteurellae isolates was suggestive of the fact that new generation antibiotics or chemotheraputic agents were found to be more effective than the old conventional drugs like sulpha preparations and oxytetracyclines.

Pasteurellosis either in pneumonic or generalized septicaemic form had been regularly reported in zoo mammals and birds. 
Table 3. Antibiogram of P. multocida isolates recovered from birds succumbed to pasteurellosis.

\begin{tabular}{|c|c|c|c|c|c|}
\hline \multirow{2}{*}{$\begin{array}{l}\text { Antibiotic } \\
\text { Chemotherapeutic } \\
\text { Agents }\end{array}$} & \multirow[b]{2}{*}{$\begin{array}{l}\text { Hornbill } \\
\text { (3) }\end{array}$} & \multicolumn{2}{|c|}{ Number resistant } & \multirow[b]{2}{*}{$\begin{array}{l}\text { Kite } \\
\text { (3) }\end{array}$} & \multirow[b]{2}{*}{$\begin{array}{l}\text { Tota } \\
\text { (26) }\end{array}$} \\
\hline & & $\begin{array}{l}\text { Hen/Cock } \\
\text { (10) }\end{array}$ & $\begin{array}{l}\text { Pigeons } \\
(10)\end{array}$ & & \\
\hline Pefloxacin & 0 & 2 & 2 & 1 & 5 \\
\hline Enrofloxacin & 0 & 1 & 2 & 1 & 4 \\
\hline Triple Sulpha & 2 & 4 & 3 & 1 & 10 \\
\hline Oxytetracycline & 2 & 7 & 7 & 2 & 18 \\
\hline Amoxycillin & 1 & 6 & 4 & 1 & 12 \\
\hline Cloxacillin & 1 & 4 & 4 & 1 & 10 \\
\hline Gentamycin & 1 & 6 & 4 & 1 & 12 \\
\hline
\end{tabular}

Figures in parenthesis indicate the number of birds tested.

Arora (1988-89) reported pasteurellosis in captive wildlife, Arora and Kumar (1988) reported pasteurellosis in Leopard, Chakraborty (1993) recorded pasteurellosis in Himalayan Wolf, Khan (1983) enlisted diseases in wildlife at Nehru Zoological Park, including pasteurellosis, Report (1978) also evidenced pasteurellosis in captive wild animals and Sen Gupta (1974) recorded pasteurellosis in wild mammals, birds and reptiles.

\section{Acknowledgement}

The authors are grateful to the Director Research (Veterinary and Animal Sciences), Rajasthan Agricultural University, Bikaner, Rajasthan and Jaipur Zoo for providing necessary facility to carry out the work.

\section{References}

Arora, B.M. (1988-89). Health monitoring and disease surveillance in captive free wildlife. Research Project Report, Centre for Wildlife Conservation, Management and Disease Surveillance, Izatnagar, U.P. Arora, B.M. and P.N. Kumar. (1988). Pasteurellosis in a Panthera tigris. Indian J. of Comp. Micro. Imm. \& Infect. Dis. 9(2): 215-226. Carter, G.R. (1967). Adv.Vet.Sci.Comp.Med. 11:321.

Chakraborty,G. and B. Maity. (1993). Pasteurellosis in himalayan wolf (Canis lupus), Indian J. of Vet. Path. 17(1): 63-64.

Khan, G.A. (1983). List of diseases recorded in the Wild animals at Nehru Zoological Park, Hyderabad. J. of Wildlife Hlth. 2: 1-90.

Report (1978). Annual Scientific Report, Div. Epidemiology, IVRI, Izatnagar, U.P.

Sen Gupta, M.R. (1974). Further notes on diseases and parasites in zoo animals, birds and reptiles. Indian J. Anim. Hlth. 13: 167-169. 